\title{
Fetomaternal outcome in pregnancies complicated by fibroid
}

\section{Leimapokpam Roshan Singh, Kaushik Mahajan*, Nandeibam Balchand Singh, Wairokpam Prabinkumar Singh, Kabita Athokpam, R. K. Jinaluxmi}

Department of Obstetrics and Gynecology, Regional Institute of Medical Sciences, Imphal, Manipur, India

Received: 12 June 2021

Accepted: 07 July 2021

*Correspondence:

Dr. Kaushik Mahajan,

E-mail: Kaushik.rims@gmail.com

Copyright: (c) the author(s), publisher and licensee Medip Academy. This is an open-access article distributed under the terms of the Creative Commons Attribution Non-Commercial License, which permits unrestricted non-commercial use, distribution, and reproduction in any medium, provided the original work is properly cited.

\section{ABSTRACT}

Background: Fibromyoma (leiomyoma) is the most common benign tumour of the uterus. Approximately $10 \%$ to $30 \%$ of women with uterine fibroids developed complications during pregnancy. The aim of the study was planned to ascertain the fetomaternal outcome in pregnancies complicated by fibroid.

Methods: A hospital based cross-sectional study was conducted among pregnant women with documented uterine fibroid who was admitted for any complication or delivered in the department of obstetrics and gynaecology, RIMS, Imphal from September 2017 to August, 2019 in the department of obstetrics and gynaecology in collaboration with department of paediatrics, Regional institute of Medical Sciences, Imphal. Detailed clinical history and sociodemographic profile were recorded in pre-designed proforma. General physical examination and systemic examination and obstetrical examination was carried out for the participants.

Results: Major proportions was in the age group of 30-39 years $(73.9 \%)$. Fibroids were more frequent in primigravida (76.1\%) followed by P1 (15.2\%) and $\geq \mathrm{P} 2$ (8.7\%). Out of 46 patients $43(93.5 \%)$ delivered by CS (69.76\%), NVD $(25.58 \%)$ and instrumental delivery $(4.65 \%)$ while 3 patients $(6.5 \%)$ undergo spontaneous abortions. Most common myoma found in this study was intramural (47.8\%) followed by submucous (34.8\%) and subserosal (17.4\%). Out of 43 deliveries most common complications found was atonic PPH $(6.97 \%)$ and placenta previa $(6.97 \%)$ followed by degenerations (2.32\%), abruptio placentae (2.32\%), malpresentations $(2.32 \%)$. Out of 43 deliveries $6.9 \%$ baby born with low birth weight, IUGR (6.9\%), IUFD (4.6\%), NICU admission (4.65\%) and early neonatal death (2.32\%).

Conclusions: Pregnancies with fibroids are considered as high-risk pregnancy associated with complications during the antepartum, intrapartum, postpartum period. Pregnant women with myoma can be advised for regular ANC along with TAS for early diagnosis and management of complication.

Keywords: Fibroid, Myoma, Myomectomy, Cross sectional study, Fetomaternal outcome

\section{INTRODUCTION}

Fibromyoma (leiomyoma) is the most common benign tumour of the uterus. Uterine myoma or fibroid or uterine fibromyoma or leiomyomata uteri is the most common monoclonal neoplasm of female genital tract. ${ }^{1}$ Fibroids are characteristically firm in consistency, but as a result of degeneration, may be soft and cystic or rock hard due to calcification. ${ }^{2}$ Vascularisation of fibroids shows rich blood supply consisting of 'blood lake' within the tumour with more than one nutrient vessel per fibroid. Venous channels are predominantly peripheral, whereas the arterial supply are both internal and peripheral. Centre of the tumour is less vascular and likely to degenerate. It is Rokitansky who gave it the proper name fibroid.

The highest incidence of myoma is found in the reproductive age group, occurring in every four out of five women. The trend in the age incidence have remained the same, the occurrence of fibroid is rare before 20 years of age, and they cease to grow after menopause. At least $20 \%$ of all the reproductive age are incidentally noted to have 
myomas during routine examination, of which majority are asymptomatic $(>50 \%)$ and occur in $20-25 \%$ of women over the age of 30 years. ${ }^{3}$ The prevalence of myoma in pregnancy ranges from $0.09-3.9 \%$ and myomas in pregnancy are associated with an antepartum complication of $10-40 \% .^{4}$ However pathological examination of removed uterus showed that the prevalence of uterine fibroid tumour may be as high as $80 \% .^{5}$

All myomas are interstitial to start with. As they enlarge, they remain as intramural, but growth often extends in the internal or external direction, becoming a submucous or subserous myoma. ${ }^{1}$ Submucous myoma may extend towards the cervix as a polyp or may extend to the surrounding structures, forming a round ligament or broad ligament myomas. Visualisation of fibroid in pregnancy can be problematic partly because of the difficulty of ultrasonography in differentiating fibroids from physiological thickening of the myometrium. ${ }^{1}$ During pregnancy $15-30 \%$ of myomas get enlarged due to increased estrogen and progestin level but most of them shrink during puerperium. ${ }^{1}$ Pregnancies associated with fibroid are usually asymptomatic and with minimal complications but sometimes adversely affect the course of pregnancy. Intramural and subserous fibroid of less than $3 \mathrm{~cm}$ are not clinically significant. ${ }^{6}$ Fibroid less than $5 \mathrm{~cm}$ in diameter tend to remain stable or decrease in size and larger fibroid $(5 \mathrm{~cm})$ tend to grow during the pregnancy. ${ }^{7}$

Effect of myoma on pregnancy depend on size, number and location of myoma. ${ }^{8}$ It increases uterine irritability and contractility, either because of rapid growth and degeneration of myomas or because of altered secretion in oxytocin activity, may interfere with normal pregnancy maintenance. The compressive effect of myomas may alter the endometrium directly and may disrupt the normal growth process of the conceptus mechanically. Compromised endometrial vascular supply and reduction in uterine blood supply may affect the placenta and fetus adversely and ultimately may result in spontaneous abortion. ${ }^{9}$

Fibroid located in uterine cavity may increase chance of miscarriage, pre-labour rupture of membranes and preterm labour. During pregnancy fibroid may undergo red degeneration causing severe lower abdominal pain. ${ }^{10}$ Fibroid may also increase risk of malpresentation, intrauterine growth restriction, abnormal implantation of placenta, placental abruption, preterm labour, obstructed labour, dysfunctional labour and increased caesarian section rate. ${ }^{8,11}$

They distort the overlying endometrium and become extruded or pedunculated in the endometrial canal. ${ }^{12}$ These complications are more commonly seen with large submucosal and retroplacental fibroids. ${ }^{13}$ Even though there is higher caesarean section rate in women with fibroids, the presence of uterine fibroids should not be regarded as a contraindication to trial of labour. ${ }^{10}$ Women with fibroid have increase caesarean section rate due to distortion of birth canal or other obstetrics reason. ${ }^{14}$ The blood flow is reduced significantly in myomas and in myometrium adjacent to them. Thus, implantation in the endometrium overlying a myoma may lead to placental ischemia and decidual necrosis, making it more susceptible to abruption. ${ }^{18}$ Submucous myomas and retroplacentally located ones and myomas with volume greater than $200 \mathrm{ml}$ (corresponding to $7-8 \mathrm{~cm}$ diameter) have a greatest risk of abruption. ${ }^{19}$ An increased rate of $\mathrm{PPH}$ has been found in pregnancies complicated by myoma, especially if myoma is $>3 \mathrm{~cm}$ and located behind the placenta. ${ }^{16}$ The risk may be increased further by caesarean delivery.

Myoma, because of its prevalence in the reproductive years, and association with many complications, has a great significance in the obstetrical outcome of a pregnant woman. A detailed study about myoma in pregnancy and its associated complication is very much needed. Therefore, it was planned to study the obstetric outcome of pregnancy with myoma in RIMS, Imphal.

\section{METHODS}

A hospital based cross-sectional study was conducted among pregnant women with documented uterine fibroid who was admitted for any complication or delivered in the department of obstetrics and gynaecology, RIMS, Imphal from September 2017 to August, 2019 in the department of obstetrics and gynaecology in collaboration with department of paediatrics, RIMS, Imphal. Patients with twin pregnancy, polyhydramnios or with any systemic diseases like diabetes, hypertensive disorder in pregnancy or any chronic illness, patients who refused to give written informed consent were excluded. The study was conducted after obtaining permission from the Research Ethics Board, RIMS, Imphal.

\section{Sample size and sampling}

Assuming the prevalence of fibroid of pregnancy in India as $13 \%$, the sample size was estimated to be 45.24 at $95 \%$ confidence interval and precision of $10 \%$, using the formula for diagnostic tests. All the Pregnant women with documented uterine fibroid who was admitted for any complication or delivered in the department of obstetrics and gynaecology, RIMS, Imphal included in this study until the sample size was reached.

\section{Study procedure}

After obtaining informed consent from the participants, the detailed clinical history including spontaneous abortion, preterm labour, premature rupture of membranes, placenta previa, abruptio Placentae, malpresentation, dysfunctional labour, degeneration, maternal weight and sociodemographic profile were then recorded. Following the socio demographic and clinical characteristics, general physical examination (pallor, oedema, neck glands, thyroid) and systemic examination and obstetrical 
examination was carried out for the participants. Fetal outcome was recorded in terms of: (a) gestational age, (b) viability- live born/still born, (c) birth weight, (d) Apgar score, (e) admission in NICU- admitted/not admitted, (f) congenital anomaly, (g) any neonatal death, (e) mode of delivery: vaginal/assisted vaginal delivery/caesarean section, and (f) complications if any. All the routine investigations including complete haemogram, urine routine examination, liver and kidney function tests, $\mathrm{ABO}$ grouping and $\mathrm{Rh}$ typing, blood sugar estimation, thyroid profile along with necessary investigations like ultrasonography (trans-abdominal) were also performed. Data was recorded in a pre-designed proforma.

\section{Statistical analysis}

Data were checked for completeness and consistency. Data was analysed using SPSS for windows version 21(IBM. Corp 1995, 2012). Descriptive statistical tools like mean, percentage and proportion were used. Association between preterm labor and fetomaternal outcome were analysed using Chi square test. $\mathrm{P}$ value $<0.05$ was considered as significant.

\section{RESULTS}

In this study, over a period of one and half years (i.e.; September 2017-March 2019) there were 13,810 deliveries and 46 cases with fibroid uterus with pregnancy were included in the study.

Table 1 shows majority of the patient were in the reproductive age range of 30-39 years (73.9\%) and 20-29 years $(23.9 \%)$.

Table 1: Age of study population $(\mathrm{N}=46)$.

\begin{tabular}{|ll|}
\hline Age group (years) & $\begin{array}{l}\text { No. of patients and } \\
\text { percentage }(\%)\end{array}$ \\
\hline $\mathbf{2 0 - 2 9}$ & $11(23.9)$ \\
\hline $\mathbf{3 0 - 3 9}$ & $34(73.9)$ \\
\hline $\mathbf{4 0}$ & $1(2.2)$ \\
\hline
\end{tabular}

Table 2 shows fibroid are found to be more common in primi. Out of 46 patients, $35(76.1 \%)$ were primi followed by $\mathrm{P} 1(15.2 \%)$ and $\geq \mathrm{P} 2(8.7 \%)$.

Table 2: Parity wise distribution $(\mathrm{N}=46)$.

\begin{tabular}{|ll|}
\hline Parity & $\begin{array}{l}\text { No. of patients and } \\
\text { percentage }(\%)\end{array}$ \\
\hline Primi & $35(76.1)$ \\
\hline P1 & $7(15.2)$ \\
\hline$\geq \mathbf{P 2}$ & $4(8.7)$ \\
\hline
\end{tabular}

Table 3 shows out of 46 patients, 36 (78.3\%) patients were admitted at term pregnancy followed by $7(15.2 \%)$ patient were between $28-36$ weeks and $3(6.5 \%)$ patient were $<28$ weeks.
Table 3: Duration of gestation at diagnosis $(\mathrm{N}=46)$.

\begin{tabular}{|l|l|}
\hline Gestational age (weeks) & $\begin{array}{l}\text { No. of patients and } \\
\text { percentage }(\%)\end{array}$ \\
\hline $\mathbf{2 8}$ & $3(6.5)$ \\
\hline $\mathbf{2 8 - 3 7}$ & $7(15.2)$ \\
\hline $\mathbf{3 7}$ & $36(78.3)$ \\
\hline
\end{tabular}

Table 4 shows out of 46 patients, $43(93.5 \%)$ patients delivered while 3 patients $(6.5 \%)$ undergo spontaneous abortion.

Table 4: Pregnancy outcome $(\mathrm{N}=46)$.

\begin{tabular}{|ll|}
\hline Pregnancy outcome & $\begin{array}{l}\text { No. of patients and } \\
\text { percentage }(\%)\end{array}$ \\
\hline Abortion & $3(6.5)$ \\
\hline Delivery & $43(93.5)$ \\
\hline
\end{tabular}

Table 5 shows intramural myoma was the commonest type of myoma accounting to $47.8 \%$ followed by submucous in $34.8 \%$, subserosal in $17.4 \%$.

Table 5: Type of myoma.

\begin{tabular}{|l|l|}
\hline Types & $\begin{array}{l}\text { No. of patients and } \\
\text { percentage }(\%)\end{array}$ \\
\hline Intramural & $22(47.8)$ \\
\hline Submucosal & $16(34.8)$ \\
\hline Subserosal & $8(17.4)$ \\
\hline
\end{tabular}

Table 6 shows $69.76 \%$ of the pregnant women underwent CS, followed by $25.58 \%$ NVD, and $4.65 \%$ by instrumental delivery.

Table 6: Mode of delivery $(\mathrm{N}=46)$.

\begin{tabular}{|ll|}
\hline Modes of delivery & $\begin{array}{l}\text { No. of patients and } \\
\text { percentage }(\%)\end{array}$ \\
\hline Cesarean section & $30(69.76)$ \\
\hline NVD & $11(25.58)$ \\
\hline Instrumental & $2(4.65)$ \\
\hline
\end{tabular}

Table 7 shows birth weight less than $2.5 \mathrm{~kg}$ were observed in $6.9 \%$, IUGR was seen in $6.9 \%$, IUFD and NICU admission was seen in $4.6 \%$.

Table 7: Neonatal outcome.

\begin{tabular}{|l|l|}
\hline Neonatal outcome & $\begin{array}{l}\text { No. of patients and } \\
\text { percentage }(\%)\end{array}$ \\
\hline Birth weight $(\mathbf{k g})$ & \\
\hline$<2.5$ & $3(6.9)$ \\
\hline$\geq 2.5$ & $40(93.02)$ \\
\hline IUGR & $3(6.97)$ \\
\hline IUFD & $2(4.6)$ \\
\hline NICU admission & $2(4.6)$ \\
\hline Early neonatal death & $1(2.32)$ \\
\hline
\end{tabular}


Table 8 shows complications were observed in $20.9 \%$. Atonic PPH occurred in $6.97 \%$; placenta previa was associated with $6.97 \%$, degeneration was seen in $2.32 \%$; abruptio placentae in $2.32 \%$, malpresentation in $2.32 \%$. No maternal death was observed in this study.

Table 8: Complication during pregnancy and delivery $(\mathrm{N}=43)$.

\begin{tabular}{|ll|}
\hline Complications & $\begin{array}{l}\text { No. of patients and } \\
\text { percentage }(\%)\end{array}$ \\
\hline Degeneration & $1(2.32)$ \\
\hline Abruptio placenta & $1(2.32)$ \\
\hline Malpresentation & $1(2.32)$ \\
\hline Atonic PPH & $3(6.97)$ \\
\hline Placenta previa & $3(6.97)$ \\
\hline Nil & \\
\hline
\end{tabular}

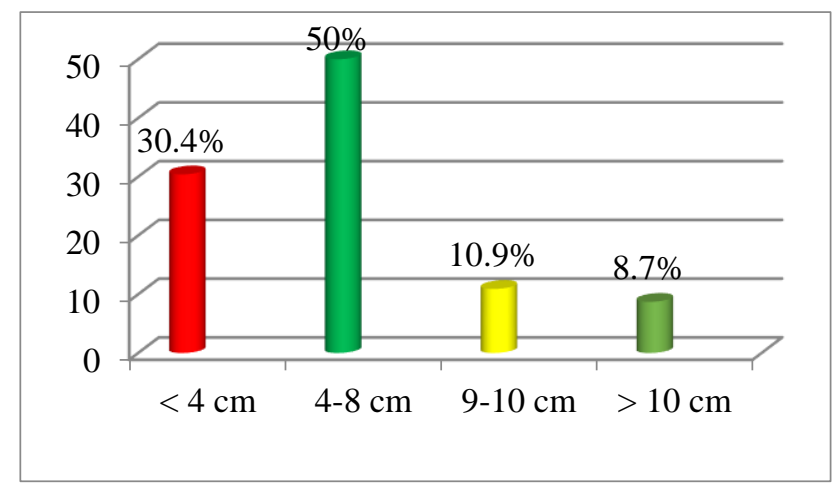

Figure 1: Most of the myomas were of the size range $4-8 \mathrm{~cm}(50 \%)$.

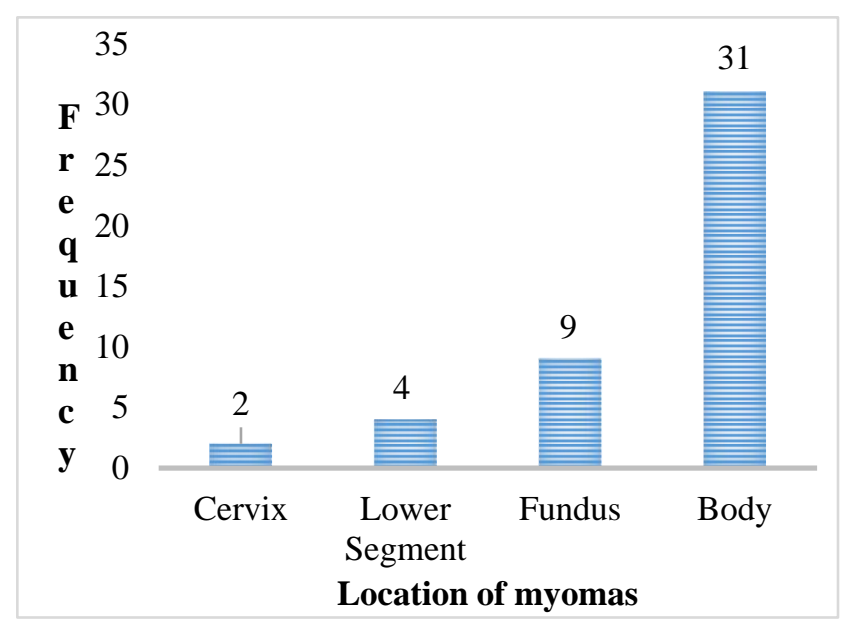

Figure 2: Shows most of the myomas $(67.4 \%)$ were present on the body of uterus.

\section{DISCUSSION}

Presence of myoma during pregnancy is potentially a serious problem. Uterine fibroid has been implicated as a cause of adverse pregnancy events. Though in some cases, it does not affect pregnancy outcome, in many cases depending upon its size, location and site of placental attachment, it can result in miscarriage, premature pre labour rupture of membranes, preterm labour, antepartum haemorrhage $(\mathrm{APH})$, postpartum haemorrhage (PPH), caesarean birth and uterine inversion. Our study was conducted to find out the obstetrical complications of pregnancy and feto-maternal outcome among pregnant women with uterine myoma admitted in department of obstetrics and gynaecology, RIMS during the period of two years from September 2017-March 2019. In the present study, myoma was present in $34(73.9 \%)$ in the age group of 30-39 years. Most of the women were primipara35(76.1\%). According to Novak's et al, the highest incidence of myoma was found in the reproductive age group, usually over the age of 30 years, and in nulliparas. ${ }^{1}$ Coronado et al observed that leiomyomas were more commonly found over the age of 35 years and in nullipara. ${ }^{27}$ Saha et al observed that the highest incidence of pregnancy with myoma was found in more than 30 years. $^{29}$

Shahida et al observed that $64 \%$ of fibroid patient with myoma belonged to the age group of 30-34 years. ${ }^{39} 55 \%$ of patient were primiparous. Aktar et al observed that pregnant women with myoma ranged from 24 to 40 years and median age was 30 years. ${ }^{30}$ Saha et al also found that the highest incidence was found in those patient with more than 30 years age group. ${ }^{29}$ Hini et al also found that majority of the pregnant women with myoma belonged to the age group between $25-35$ years. ${ }^{36}$ They also found that women in the study group were mostly nulliparous than controls $(56.25 \%$ vs $12 \%)$. Ramalingam et al found that fibroid were more frequent in multigravida $73.3 \%$ compared to primigravida $26.6 \% .^{21}$ Radhika et al found that fibroid were more frequent in multigravida compared to primi. $^{22}$ Majeed et al observed that pregnant women with myoma belong to the age group 25 to 35 years. ${ }^{38}$

Ramalingam et al observed that $90 \%$ of the pregnant women with myoma crossed 37 completed weeks. ${ }^{17}$ Radika et al found that $73.3 \%$ of the patient had continued their pregnancy till term. ${ }^{22}$ Noor et al observed $90 \%$ of the pregnant women with myoma reach upto term. ${ }^{31}$ In the present study $78.3 \%$ of the pregnant women with myoma crossed 37 completed weeks. In the present study women were having 22 (47.8\%) intramural, 16 (34.8\%) submucosal, $8(17.4 \%)$ subserous type of uterine myoma. Saha et al also observed that the women were having $10 \%$ submucous, $74 \%$ intramural and $16 \%$ subserous. ${ }^{26}$ In the present study, there are $3(6.5 \%)$ abortion. Sailesh et al observed $11.1 \%$ spontaneous abortion in their study. ${ }^{34}$ Ramalingam et al observed abortion in $10 \%$ of the pregnant women with myoma. ${ }^{21}$ Toshimitsu et al found abortion in $16 \%{ }^{24}$ Saha et al found abortion in $16 \% .{ }^{29}$ Tchente et al found abortion in $11.3 \% .^{32}$ In the present study, pre-term labour was observed in 7 (15.2\%). Shella et al observed preterm labour in $10 \%$ of the patient. ${ }^{31}$ Rice et al observed preterm labour in $21.5 \%{ }^{19}$ Tasleem et al observed preterm labour in $10 \%$ of the patient. ${ }^{23}$ Totshimitsu et al found preterm labour in $24 \% .{ }^{24}$ Rice et al observed preterm labour in $21.5 \% .{ }^{19}$ Saha et al observed 
preterm labour in $18 \% .{ }^{29}$ Tchente et al observed preterm labour in $22.5 \% .{ }^{32}$ In the present study abruptio placentae was observed in one (2.2\%) pregnant woman with myoma. Aydeniz et al observed that retro placental submucous myomas increased the risk of abruptio placentae (3.2\%). ${ }^{35}$ Rice et al observed that abruptio placentae occurred in 2 $(2.5 \%)$ patient. ${ }^{19}$ Saha et al observed abruptio placenta in $8 \%$ of the pregnant women with myoma. ${ }^{29}$ In the present study placenta praevia was found in four cases $(6.5 \%)$. Ramalingam et al observed placenta praevia in $3(10 \%)$ pregnant women with myoma. ${ }^{21}$

In the present study malpresentation breech was observed in $3(6.6 \%)$ pregnant women with myoma. Hina et al found an increased association of breech presentation with myoma $(38.46 \%){ }^{40}$ Tasleem et al observed malpresentation in $12 \%$ of the patient. ${ }^{23}$ Saha et al found malpresentation in $14 \%$ of the pregnant women with myoma. ${ }^{29}$ Aktar et al observed malpresentation in $5.4 \% .{ }^{26}$ In the present study, degeneration of myoma was observed in $1(2.2 \%)$ pregnant woman. Tasleem et al observed red degeneration in $4 \% .{ }^{23}$ Sailesh et al in their study observed an increase in size of myoma and in echo texture on sonography and had acute pain due to degeneration in $11 \%{ }^{33}$ Aktar et al found degeneration in $14.5 \% .^{26}$

Adeniz et al in their study showed that retro placental submucous myomas increased the risk of fetal growth restriction (14\% versus $6.6 \%) .{ }^{35}$ In the present study fetal growth restriction was observed in $4(8.7 \%)$ pregnant women with myomas. Noor et al observed IUGR in $6.66 \% .{ }^{31}$ Saha et al found fetal growth restriction in $14 \%$ of the pregnant with myoma. ${ }^{29}$ Aktar et al observed IUGR in $3 \% .{ }^{26}$ In the present study $31(67.4 \%)$ pregnant women underwent CS. In the present study, the rate of CS was markedly increased. Misbah et al also found a similar increase in CS rate in women with myoma $63.5 \% .^{20}$ Shella et al observed $70 \%$ of the pregnant women with myoma were delivered by $\mathrm{CS} .{ }^{31}$ Ramalingam et al observed that CS was performed in $16(59.2 \%)$ pregnant women with myoma. ${ }^{21}$ Akhtar et al also found increase in CS in the pregnant patient with myoma $31(56.36 \%){ }^{30}$

Tasleem et al observed caesarean section was performed in $46.1 \% .^{23}$ Toshimitsu et al observed CS in $51 \% .^{24}$ In the present study atonic PPH occurred in 6 patients $(9.7 \%)$. Sailesh et al observed an $11 \%$ association of severe PPH in women with myoma. ${ }^{33}$ The study conducted by Akhtar et al observed that $3(5.4 \%)$ pregnant women with myoma had PPH. ${ }^{7}$ Andreani et al showed that the presence of multiple myomas was the only parameter. ${ }^{37}$ Sarwar et al observed PPH in $26.67 \%$ in the pregnant patient with myoma. ${ }^{25}$ Akhtar et al also observed PPH in 5.4\%. ${ }^{30}$ Noor et al found PPH in $33.33 \% .{ }^{31}$ Radhika et al observed PPH in $33.3 \% .^{22}$ Saha et al observed intrauterine fetal death in $8 \%$ of the cases. ${ }^{29}$ In the present study, there was 2 fetal death $(4.3 \%)$. Sarwar et al observed $13.33 \%$ intrauterine deaths and one neonatal death. ${ }^{25}$

\section{Limitations}

The major limitations of this study were the small sample size and restriction of the study population to a state referral hospital. So, the results of this study may not reflect the actual scenario in the general population. Hence, we should analyse the results of this study with caution. Beside the limitatations, this study has provided the basic information on fetomaternal outcome in pregnancies complicated by fibroid in our set up and also guides to conduct further studies on this topic be carried out in different settings.

\section{CONCLUSION}

Pregnancy with uterine fibroid is considered as high-risk pregnancy. Most of them are asymptomatic but may adversely affect course of pregnancy and labour depending upon their location and size. Myoma is the most common benign tumour of the pelvis associated with the woman in reproductive age group, mostly after 30 years of age. Fibroids during pregnancy lead to increase in rate of CS due to high incidence of dysfunctional labour and malpresentation. Pregnancy with myoma is often considered a high-risk pregnancy as it is associated with many complications like abortion, preterm labour, premature rupture of membrane, abruptio placentae, placenta praevia, pain due to degeneration, intrauterine growth restriction, malpresentation, dysfunctional labour, PPH, decreased Apgar score, fetal anomalies, fetal death, etc. Pregnant women with myoma can be advised for regular ANC along with TAS for early diagnosis and management of complication. Casearean myomectomy in selected cases may be beneficial.

\section{Funding: No funding sources}

Conflict of interest: None declared

Ethical approval: The study was approved by the Institutional Ethics Committee

\section{REFERENCES}

1. Paula J, Adams H. Benign Diseases of the Female Reproductive Tract. In: Jonathan SB, Rebecca DR, Timothy CH, eds. Berek and Novak's Gynaecology. 14th ed. New Delhi: Lippincott Williams and Wilkins; 2007. 469-471.

2. Quyang DW, Norvitz ER. Management of pregnant women with leiomyomas, 2017. Available at: http://www.uptodate.com/patients/content/topic.do?topi c key $=\sim$ ewppe YOKn3st Roe.com. Accessed on 02 June 2021.

3. Vollenhoven BJ, Lawrence AS, Healy DL. Uterine fibroids: a clinical review. $\mathrm{Br} \mathrm{J}$ Obstet Gynaecol. 1990;97(4):285-98

4. Katz VL, Dotters DJ, Doegmuller W. Complications of uterine leiomyomas in pregnancy. Obstet Gynaecol 1989;73(6):563-5.

5. Umezurike C, Waboso P. Successful myomectomy during pregnancy: a case report. Reprod health. 2005;2(1):2-6. 
6. Rosati P, Bellati U, Exacoustos C, Angelozzi P, Mancuso $\mathrm{S}$. Uterine myoma in pregnancy: ultrasound study. Int $\mathrm{J}$ Obstet Gynaecol 1989;28(2):109-17.

7. Akhtar N, Sultana S, Zabin F. Successful outcome of pregnancy with large fibroid uterus-A case report. Bangladesh J Obstet Gynaecol. 2013;25(2):87-9.

8. Wallach EE, Buttram VC, Reiter RC. Uterine leiomyomata: etiology, symptomatology, and management. Fertil Steril. 1981;36(4):433-45.

9. Wallach EE, $\mathrm{Vu} \mathrm{KK}$. Myomata uteri and infertility. Obstet Gynaecol Clin North Am. 1995;22(4):791-9.

10. Davis JL, Kay HH, Mazumder S, Habel CJ, Baley K, Sassoon D. Uterine leiomyomas in pregnancy: a prospective study. Obstet Gynecol. 1990;75:41-4.

11. Fleischer AC, Shah DM, Entman SS. Sonographic evaluation of maternal disorders during pregnancy. Radio Clin North Am. 1990;28(1):51-8.

12. Cornforth T. 10 things to know about uterine fibroid tumours, 2017. Available at: http://womenshealth.about.com/od/fibroidtnowabtfibroi ds.html. Accessed on 02 June 2021.

13. Ciavattini A, Clemente N, Delli CG, Giuseppe J, Giannubilo SR, Tranquilli AL. Number and size of uterine fibroids and obstetric outcomes. J Materl Fetal Neonatal Med. 2015;28(4):484-8.

14. Lefebvre G, Vilos G, Allaire C, Jeffrey J, Arneja J, Birch $\mathrm{C}$, et al. The management of uterine leiomyomas. Obstet Gynaecol Can. 2003;25(5):396-418.

15. Strobelt N, Ghidini A, Cavallone M, Pensabene I, Ceruti P, Vergani P. Natural history of uterine leiomyomas in pregnancy. J Ultrasound med. 1994;13(5):399-401.

16. Phelan JP. Myomas and pregnancy. Obstet Gynecol Clin North Am. 1995;22(4):801-5.

17. Roberts WE, Fulp KS, Morrison JC, Martin JN. The impact of leiomyomas on pregnancy. Aust N Z J Obstet Gynaecol. 1999;39(1):43-7.

18. Forssman L. Distribution of blood flow in myomatous uteri as measured by locally injected 133Xenon. Acta Obstet Gynecol Scand. 1976;55(2):101-4.

19. Rice JP, Kay HH, Mahony BS. The clinical significance of uterine leiomyomas in pregnancy. A $\mathbf{J}$ Obstet Gynaecol. 1989;160(5):1212-6.

20. Javed M, Tariq R, Rashid M. Effect of Uterine Fibroid on Pregnancy Outcome. PJMHS. 2010;4(4):476-78.

21. Poovathi M, Ramalingam R. Maternal and Fetal Outcome in Pregnancy with Fibroids: A Prospective Study. Int J Sci Stud. 2016;3(11):169-72.

22. Radhika BH, Naik K, Shreelatha S, Vana H. Case series: pregnancy outcome in patients with uterine fibroids. JCDR. 2015;9(10):1.

23. Raja KS, Tasleem H. Effects of uterine leiomyoma on the course of pregnancy and labour. Rawal Med J. 2009;34(1):79-81.

24. Koike T, Minakami H, Kosuge S, Usui R, Matsubara S, Izumi A, et al. Uterine leiomyoma in pregnancy: its influence on obstetric performance. J Obstet Gynaecol Res. 1999;25(5):309-13.
25. Sarwar I, Habib S, Bibi A, Malik N, Parveen Z. Clinical audit of fetomaternal outcome in pregnancies with fibroid uterus. J Ayub Med Col Abbottabad. 2012;24(1):79-82.

26. Qidwai GI, Caughey AB, Jacoby AF. Obstetric outcomes in women with sonographically identified uterine leiomyomata. Obstet Gynaecol. 2006;107(2):376-82.

27. Coronado GD, Marshall LM, Schwartz SM. Complications in pregnancy, labor, and delivery with uterine leiomyomas: a population-based study. Obstet Gynaecol. 2009;95(5):764-9.

28. Klatsky PC, Tran ND, Caughey AB, Fujimoto VY. Fibroids and reproductive outcomes: a systematic literature review from conception to delivery. A J Obstet Gynaecol. 2008;198(4):357-66.

29. Saha MM, Mondal D, Biswas SC. Pregnancy with leiomyomas uteri and feto-maternal outcomes. $\mathrm{Al}$ Ameen J Med Sci. 2016;9(2):96-100.

30. Nasim A. Effects of fibroid on pregnancy and mode of delivery. J Med Sci. 2016;24(3):167-70.

31. Noor S, Fawwad A, Sultana R, Bashir R, Jalil H, Suleman N. Pregnancy with fibroids and its and its obstetric complication. J Ayub Med Col Abbottabad. 2009;21(4):37-40.

32. Tchente CN, Fogaing AD, Tejiokem MC, Nana PN, Mbu R, Leke R. Pregnancy outcome in a group of Cameroonian women with uterine fibroids. Gynecol Obstet Biol Reprod. 2009;38(6):493-9.

33. Shailesh K, Anahita P, Aparna H, Sangeeta K, Miti A, Ambuja VR. Pregnancy with fibroids. J Obstet Gynecol Ind. 2004 ;54(4):361-2.

34. Koike T, Minakami H, Kosuge S, Usui R, Matsubara S, Izumi $\mathrm{A}$, et al. Uterine leiomyoma in pregnancy: its influence on obstetric performance. J Obstet Gynaecol Res. 1999;25(5):309-13.

35. Aydeniz B, Wallwiener D, Kocer C, Grischke EM, Diel IJ, Sohn C, et al. Significance of myoma-induced complications in pregnancy. A comparative analysis of pregnancy course with and without myoma involvement. Z Geburtshilfe Neonatol. 1998;202(4):154-8.

36. Hina K, Nudrat E, Tabassum S. Pregnancy associated with fibroids: complications and pregnancy outcome. J Coll Physicians Sugr Pak. 2002;12(12):731-4.

37. Andreani M, Vergani P, Ghidini A, Locatelli A, Ornaghi S, Pezzullo JC. Are ultrasonographic myoma characteristics associated with blood loss at delivery? Ultrasound Obstet Gynecol. 2009;34(3):322-5.

38. Majeed T, Waheed FA, Sattar Y, Mobusher I, Saba K. Impact of uterine fibroids on the obstetric performance of the women; complications and pregnancy outcome. Pak J Med Sci. 2011;5:274-7.

39. Shahida J, Rinku G, Devi S. Maternal and fetal outcome in fibroid complicating pregnancy in a tertiary care centre. JMSCR. 2017;5(1):15543-46.

40. Dutta DC. Textbook of obstetrics including perinatology and contraception. 9th ed. New Delhi: Jaypee brothers medical publishers; 2017.

Cite this article as: Singh LR, Mahajan K, Singh NB, Singh WP, Athokpam K, Jinaluxmi RK. Fetomaternal outcome in pregnancies complicated by fibroid. Int J Reprod Contracept Obstet Gynecol 2021:10:3174-9. 